\title{
Speech-language therapists supporting foundation-phase teachers with literacy and numeracy in a rural and township context
}

\author{
Anna-Marie Wium \\ Brenda Louw \\ University of Pretoria
}

\author{
Irma Eloff \\ Faculty of Education, University of Pretoria
}

Correspondence to: A Wium (awium@ul.ac.za)

\begin{abstract}
Language is required for learning, but educators often find it difficult to facilitate listening and language skills while they have to adapt to a new national curriculum with an outcomes-based approach for which they have not necessarily been adequately trained. A multifaceted support programme was developed for foundation-phase educators to facilitate listening and language for literacy and numeracy, with a particular focus on language for numeracy. The aim of the research was to determine the value of this particular support programme for foundation-phase educators in two different contexts (a semi-rural and a township context). A mixed methods approach with a concurrent, equal status triangulation design was used, where qualitative data were transformed to quantitative data in order to be compared in a matrix. The results show that the participants benefited to varying degrees from the programme. The combination of workshops, practical and mentoring components proved to be an effective means of support. The results indicate a need for pre-training selection procedures as more effective support can be provided to homogeneous groups.
\end{abstract}

Keywords: educator support, language competence, speech-language therapists

\section{Introduction \\ Background}

Benchmark studies (The TIMMS \& PIRLS International Study Centre, 2007) pointed out that foundation-phase learners in the South African education system have not developed the basic reading skills required for learning and that learners who study in an indigenous language lack the necessary language skills for numeracy. This implies that the majority of learners in South Africa are not receiving quality education, which can be considered a violation of their constitutional rights. To improve learners' performance in literacy and numeracy, educators in the foundation phase would benefit from the support of speechlanguage therapists (SLTs) to facilitate these aforementioned skills. Effective support requires the SLT to collaborate with district facilitators, as well as educators and their schools. Such collaboration contributes to meeting the special educational needs of learners (Paradice, BaileyWood \& Davies, 2007). SLTs with their specialised knowledge of communication and language are particularly equipped to support educators to facilitate listening, speaking, reading and writing. SLTs working in education contexts therefore have a dual focus - to support learners, but also educators.

Within a collaborative and consultative approach, this study developed a multicomponent continued professional development (CPD) programme for foundation-phase educators to facilitate listening and language skills, particularly the language skills required for numeracy. The research determined the value and benefits of such a programme for the participants. The reasons for developing such a CPD programme include issues related to language use, a new national curriculum statement (NCS), and the specific training needs of educators, as well as the need for early childhood development programmes to enhance school readiness of learners.

\section{Language-related issues}

Many young learners in South Africa struggle to develop ageappropriate language skills because of an inherent pathology (e.g. a specific language disorder or a language delay) and/or barriers in their learning environment. Receptive and expressive language skills (spoken and written) are the basis for learning and the entire curriculum (Paradice et al., 2007). A delay in language development during the early years causes learners to fall behind and eventually drop out. This is a particular problem in South Africa, a country where scientific and technological expertise and skills are needed (Department of Education, Gauteng, 2007).

An escalating number of learners learn in a language other than their home language (L1). In Gauteng, 33\% of the learners receive instruction in their second or third language (Department of Education Chief Directorate: Quality Assurance, 2002). Also, in many classrooms the $\mathrm{L} 1 \mathrm{l}$ of the educator is not the same as the L1 of the learners. With only home support of their mother tongue, these learners lag behind in the acquisition of literacy (O'Connor \& Geiger, 2009). Owing to the diversity of language and culture in the South African context, the language of learning and teaching (LoLT) in classrooms is a contentious issue with no straight answers.

Since the new dispensation has come into power, there has been a shift in the demographic, cultural and linguistic composition of classrooms, which complicates the choice of the LoLT. Educators find such complexity in terms of language use difficult to deal with and often opt for a middle ground by using English as the LoLT. Often educators have a different L1 than the LoLT. Considering that SLTs have expertise in language and phonetics, they can make a significant contribution to the acquisition of literacy skills (e.g. reading, speaking, writing and listening). SLTs working within a consultative and collaborative model of support are required to provide educators with workshops to facilitate language- and literacy-related skills (Moodley, Chetty \& Pahl, 2005).

\section{New national curriculum statement}

Alongside the above challenges, educators currently have to adapt to a new national curriculum statement (NCS) that is based on an outcomes-based education (OBE) approach. Many educators, especially those in previously disadvantaged areas, find it difficult to implement the NCS as they are not necessarily equipped to deal with these changes from the 'old' system (Gouws \& Dicker, 2006). As a result there is a 
need for high-quality staff development and training. Currently, many educators are still struggling to deal with the challenges brought about by the legacy of apartheid, for example teaching large classes, being undertrained and underqualified, as well as coping with insufficient facilities and resources. These challenges affect educators' morale. As the general attitude of educators may have a significant impact on learners' performance, it is important to counteract low morale by providing additional support (Killen, 2007).

\section{Training needs of educators}

International research (Girolametto, Weitzman, Lefebvre \& Greenberg, 2007) indicates that many educators have little or no special training to effectively teach learners who experience (or who are at risk of developing) barriers to learning. Earlier reports (Badroodien, Gewer, Roberts \& Sedibe, 2002) estimated that 86000 educators in South African public schools were underqualified, and more recently it was reported (Davids, 2009) that almost a third of the educators lack appropriate qualifications. Many of those educators who are unqualified teach grade $\mathrm{R}$, which is a very important stage for young learners as they are being prepared for grade 1. Consequently, CPD of educators, particularly in the foundation phase, has become a national priority to increase performance in the literacy and numeracy learning areas (Creecy, 2009). SLTs working in the education environment can make a significant contribution to this end because of their expertise in the acquisition of language for learning.

\section{School readiness and the need for early childhood de- velopment}

In South Africa, $40 \%$ of all children come from extremely impoverished backgrounds where low literacy levels prevail (Botha, Maree \& de Witt, 2005) and learners have limited access to learner-support materials. Such learners may not enjoy the stimulation and learning experiences that promote school readiness. Therefore, learners from low socioeconomic schools (SESs) need to be supported to overcome their potential developmental delays, particularly in the foundation phase, so as to prevent future learning problems.

Although several studies were identified that focused on literacy and language, and particularly the vocabulary required for numeracy (Botha et al., 2005; Pluddemann, Mati \& Mahlalela-Thusi, 1998; Reed, Davis \& Nyabanyaba, 2003; Setati, 1999), limited research was available that was pertinent to the support of foundation-phase educators in facilitating such skills. One of the reasons for developing this particular CPD programme was to support foundation-phase educators to facilitate improvement in their abilities to teach literacy and numeracy. Previous studies were mainly descriptive in nature, and made use of quantitative data. Mixed methods research, such as was used in this particular study, is extremely suitable for use in educational contexts (McMillan \& Schumacher, 2006).

\section{The CPD programme developed by this study}

This study developed the framework for a continued support process for foundation-phase educators, as well as the training material to support this.

\section{Framework for a support programme}

The proposed programme consisted of training, practical and mentoring components to support educators in facilitating listening and language skills for literacy, and with a particular focus on the language of numeracy.

These three components (illustrated in Figure 1) were designed to augment each other in empowering foundation-phase educators to facilitate listening and language skills in learners. The support provided by the training component was aimed at the acquisition of foundational competence. It consisted of three full-day workshops that focused on subject knowledge of facilitating listening and language, as well as the language for numeracy as stipulated in the NCS. A practical and a mentoring component were also included, as limited benefit can be expected from one-day workshops (Massel \& Goertz, in Roberts, 2002). Research (Sowden, 2007) has shown that elements of reflection, as well as opportunities to gain first-hand experience ('knowledge in practice') (Adler, Slonimsky \& Reed, 2003), enhance learning.

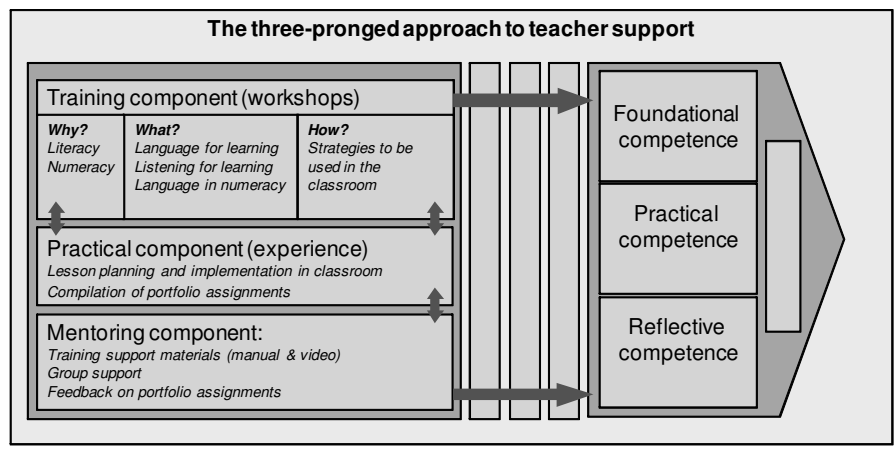

Fig. 1. A model of the CPD programme for foundation-phase educators.

\section{The training component}

The training component consisted of the development of the training material and design of three full-day workshops per annum. The three workshops integrated the principles of adult learning, learning preferences and OBE. In the semi-rural context the workshops were conducted on Saturdays; in the urban context on a school holiday and public holidays. The workshops provided participants with strategies and activities to facilitate listening and language skills, which were firstly demonstrated. Strategies included the use of a theme with supporting stories, songs, rhymes and crafts, which in many instances were selfconstructed. Such strategies were used to facilitate the four language systems required by the NCS (reading, speaking, listening and writing). Participants had the opportunity to practise these strategies in role play in the workshop before applying them in their classrooms. Based on the whole-language approach (Goodman, 1986), the use of a theme created several language-rich experiences and allowed the learners to develop the vocabulary related to a specific topic, and integrate skills across the curriculum. The facilitator of these workshops was a qualified SLT with experience in the field of educator support and adult learning.

The training material developed for the workshops included basic theoretical background for educators to understand the importance of listening and language skills with regard to the NCS. The three workshop topics and the rationale for their selection were as follows:

- 'Listening for learning'. Learners need to learn the art of listening actively, attentively and analytically in order to learn. As listening and language are interrelated, the facilitation of auditory processing skills needs to be included as part of an integrated approach in the classroom (Bellis, 2003). Such an integrated intervention approach also includes phonological awareness and phonemic processing (Richards, 2004).

- 'Language for learning'. Emergent literacy involves both written language awareness and phonological awareness (Justice \& Ezell, 2001), which are both based on normal oral language (particularly vocabulary development). Age-appropriate oral language development is required for the development of reading competence, and therefore oral language proficiency is regarded as predictive of reading achievements as well as other written language achievements at a later stage (Catts, Fey, Zhang \& Tomblin, 2002). This specific programme supported a 'balanced approach' as current best practice for the facilitation of literacy (Justice \& Kaderavek, 2004). Such an approach firstly creates opportunities to develop an understanding of the language and then uses this understanding as the basis to teach discrete skills within a phonics-oriented, code-based approach (Justice, Skibbe \& Ezell, 2006).

- 'Language for numeracy'. The aim of the workshop 'Language for numeracy' was to alert educators to the importance of language use 
in numeracy and to empower them to facilitate the acquisition of the vocabulary required for numeracy development (Gawned, 1993). Towards the end of the grade $\mathrm{R}$ year learners should have acquired an understanding of the language of measurement, position in space, selection criteria for sorting, exploring, building, and matching with shapes. When considering that numeracy is: '... the language or system of thought' (Bullock, 1994), and mathematics is '... abstract and platonic and based on absolute truths about relations among ideal objects' (Steen, 2001), then the importance of the vocabulary that develops from this emergent phase of numeracy becomes evident as it provides a basis for mathematics.

\section{The practical component}

The practical component required participants to implement strategies in the classroom and then to complete portfolio assignments. The implementation of listening and language strategies was directed at skills acquisition to develop the educators' practical competence at applying the skills learnt. The participants were required to prepare their lesson plans within a theme for 3 weeks following training, to implement the strategies learnt in the workshops, and to monitor the participation of at least three learners in the class (a competent learner, an average learner and a weak learner) on a weekly basis by completing a scaled checklist that was provided by the course facilitator.

\section{The mentoring component}

Throughout the process of engagement the educators were supported by a mentoring component that was aimed at developing their reflective competence. Their portfolios with lesson plans and teaching materials were assessed and each participant received individualised feedback. The four participants from each school included in the programme also supported each other by planning their lessons as a group, and by a weekly peer review when implementing the strategies in class. Furthermore, ongoing support provided by the district facilitators at school level enhanced the effect of the training.

The evaluation of a programme is an important phase of its development. This article specifically focuses on the gains made by the participants from attending this multifaceted programme.

\section{Research methods}

This article focuses on the gains made by the participants in knowledge, skills and attitude as these demonstrate the effect of the multifaceted support provided (training, mentoring and opportunities for application in the classroom). Ethical clearance was obtained from the University of Pretoria Research Proposal and Ethics Committee, and approval from the Gauteng Provincial Department of Education was sought to conduct the research in schools. A concurrent, equal status triangulation design was used where qualitative data were transformed into quantitative data. The research was conducted in two previously disadvantaged settings (semi-rural and township schools) for one year each consecutively.

\section{The participants}

The participants were selected by using convenience sampling (Leedy \& Ormrod, 2005) as the provincial Department of Education prioritised specific schools in these regions in an effort to redress previous imbalances in investments in schools. Although participants volunteered to participate in the research, one educator from each grade level in the foundation phase (grades R - 3) from 12 schools in each context was selected per annum $(n=96)$. Three schools in the township context did not have any grade $\mathrm{R}$ classes in the school, in which case the grade $\mathrm{R}$ classes from the feeder schools were included.

\section{Data collection and analysis}

All interested educators were invited to attend the briefing meeting at a central venue at a school, and those who wanted to participate were required to give informed consent. Quantitative data were collected by means of questionnaires (at the briefing meeting, as well as before and after workshops), portfolio assignments and attendance registers. The questionnaires, however, were self-constructed, which in itself posed a threat to reliability and validity. To increase the validity of the questionnaires, the questions were first reviewed by a language editor. The content of the questions were scrutinised by two experts in the field, and the clarity of questions and ease of use was evaluated by three potential participants who were not included in the study. A statistician reviewed the questions and layout prior to use to ensure ease of use and accurate data capturing. A pilot study (with 12 participants) developed the questions and the data collection procedure. The reliability was increased through repetitive use (six times) over a prolonged period of 2 years within two different contexts. The reliability was compromised by factors related to timing, the use of English and low literacy levels of some of the participants.

Descriptive statistics, regression and factor analysis were employed to analyse the data. The quantitative data were statistically analysed and displayed as graphs and figures.

Eight focus groups (using a nested design) (Leech \& Onwuegbuzie, 2005), a research journal consisting of diary entries made by the researcher following each significant event, testimonials, and various correspondence provided qualitative data that were transcribed and coded, and categorised within themes. The support programme was evaluated using a logic model approach (W. K. Kellogg Foundation, 2004) consisting of input, process, output, and outcomes. Information was coded and categorised by using ATLAS-ti software. The research questions were placed within the logic model framework and codes which answered these questions were categorised accordingly. These codes and categories (with their accompanying phrases/keywords) were listed and entered in an Excel spreadsheet and grouped within the theme structure provided by the logic model (W. K. Kellogg Foundation, 2004).

Once both quantitative and qualitative data had been analysed, the data in the qualitative strand were translated to quantitative data using a binary scale (Creswell \& Plano Clark, 2007). The value of 1 was assigned to items that confirmed or positively described or supported the codes categorised under specific themes to answer the research question, and the value of 2 was assigned to all items that refuted or contrasted the items categorised under a specific theme.

\section{Results and discussion}

Owing to the nature of the research design, the qualitative inferences are discussed first, followed by a discussion of the results obtained from the quantitative strand. Next, the results from both strands are converged in a matrix. The results of the 'entire group' who attended each workshop and the 'core group' are provided. The latter refers to those participants who signed informed consent at the onset of the programme, and who attended all the workshops and completed the portfolio assignments. The 'entire group' refers to all the participants who attended one or more of the workshops and compiled one or more portfolios. Although the workshops were well attended, there was a high level of attrition (35\%) from the original group over the course of the programme. Participants from the original group who could not attend workshops sent replacements, who did not provide informed consent, and therefore the data obtained from these individuals could not be included in the research. The data from the 'entire group' were nevertheless used for comparison with the results from the 'core group' to emphasise a particular point when deemed necessary (McMillan \& Schumacher, 2006).

\section{Qualitative assessment of knowledge and skills gains by participants}

The results with regard to the acquisition of knowledge and skills in the qualitative strand of the research are discussed according to the levels of knowledge and skills acquisition described by Miller and Watts (1990) and presented in Table I. The specific codes used in the qualitative analysis are in italics and parenthesised. 


\section{Table I. Qualitative inferences re gains made in knowledge and skills by the participants}

\section{Level of knowledge and skills acquisition}

Level 1

The use of terminology

Level 2

Understanding of concepts

Level 3

Implementation of strategies

Level 4

Teaching of others

\section{Gains made}

The acquisition of new terminology was confirmed by $90 \%$ of items coded as 'terminology' ( $n=83$ The use of new terminology was, however, not generalised during the training as became evident when $64 \%(n=14)$ of the items were coded as 'inability to recall the information'. The participants' inability to recall the terminology also may have been related to their limited language proficiency in English as is evident from the following example:

Participant: 'I am talking about, I forgot the thing that you showed us. The ... the - when you taught the kids the heavy, heavier...

Trainer: The scale?'

Participant: The scale. Yeah!'

When participants could not recall the correct terminology, they described the concepts in their own words. Knowledge acquisition, however, was on the 'awareness level', which, according to Bloom's taxonomy of the knowledge domain (Anderson \& Krathwohl, 2001), is the lowest level of acquiring new knowledge and is related to 'shallow learning' Such knowledge is not sufficient for participants to apply in their classrooms (Miller \& Watts, 1990).

Participants gained in 'understanding' of the concepts taught in the workshop as confirmed by $93 \%$ $(n=43)$ of the items categorised in this regard. Participants gained a new understanding of concepts (e.g. some of the participants admitted that they had never addressed the concept of 'estimation' or 'three-dimensionality' in their numeracy lessons prior to training, because they did not understand the concept or how to teach it). The participants' language proficiency in English was closely related to their understanding of the concepts.

The participants had different levels of prior knowledge before the workshops. This is because not all the participants had similar qualifications, or were on similar levels of competence when they entered the programme, and therefore they differed in their understanding of the material as can be seen from the following example:

'T: If I just think of the lady, who just thinks of 'adjectives', but they are 'prepositions'.

Educators can only teach what they understand themselves.

Once the concepts were explained in the workshops and the material was understood, the participants were able to 'implement' the strategies in their classrooms. Of the coded items $88 \%(n=377)$ were positive. The participants were convinced that these new skills would help them to improve their teaching and that their learners would benefit. There was also evidence of a 'change in teaching practice', which was confirmed by $91 \%$ of the 44 items coded as such.

The participants felt ( $87 \%$ of the 45 items coded) that the training helped them to become more 'competent' as they had learnt to integrate various assessment standards and learning objectives in one activity, which some said they could not do previously. Such an integrated approach to teaching is inherent to OBE and the NCS (Gauteng Department of Education, 1997).

There was also evidence that some of the participants found it easier to do their 'lesson planning' ( $80 \%$ of the 25 items coded), as illustrated by the following quote:

'Most of our educators had problems with planning our lessons. Or creating LO's. I am so perfect now. I can now use the one LO and apply it to another - we kill two LOs. It also help us to be creative.' (LO = learning outcomes)

The training helped some participants to become more independent of commercial programmes purchased by their schools. Those participants who managed to develop their own lesson plans gained in confidence, which in turn could result in improved learner achievement (Killen, 2007). However, the portfolio assessments revealed that in several instances the lesson plans were incomplete and did not take the needs of individual learners into account. Regardless of the educator's level of expertise, thoughtful lesson planning is necessary to make the learning experience in the classroom purposeful, effective, and efficient. Incomplete and insufficient lesson planning may lead to ineffective teaching and learning.

A few participants experienced themselves as becoming more 'creative and innovative' (89\% of 9 items coded) as they had acquired new 'strategies', while others reported to have gained new ideas to implement in class $(n=28)$. In one school the participants collected polystyrene from the refuse dump to cut out three-dimensional shapes. This particular group of participants testified that the workshop facilitated their understanding of three-dimensionality, which simultaneously reflects on poor content knowledge prior to the training.

There was also evidence that some of the participants experienced the workshops as being helpful in dealing with 'diversity and multilevel teaching' ( $79 \%$ of the 14 items coded). The participants derived satisfaction from including all learners in the activities, as they had felt guilty about not supporting some learners in a more efficient manner. The completion of the portfolio assignments allowed some participants to identify the 'slow learners' who required more time to master the new strategies. Although the participants applied the strategies in their classrooms, it does not imply that they have become fully competent as 'implementation' represents only the third of five levels of acquiring competence (Miller \& Watts, 1990). The portfolio assignments bore evidence that many of those who implemented the strategies still required some level of support.

A few participants were empowered to such an extent that they were able to 'help or train the colleagues' $(n=21)$ (e.g. one participant took a small group of her learners from class to class to demonstrate the strategies). This signifies the fifth and final level of knowledge acquisition described by Miller and Watts (1990), where a few participants were able to successfully apply their newly acquired knowledge and skills, and to train others in the application thereof.
Although the participants gained in knowledge and skills, they did not gain equally. The results indicate that a relatively small number of items were coded as confirmative for the more advanced levels of knowledge as described by Bloom (Anderson \& Krathwohl, 2001) and skills acquisition described by Miller and Watts (1990). A much higher number of items were coded for the more basic levels of knowledge. The implication is that although knowledge and skills were acquired, learning occurred more towards the 'shallow' end of the knowledge and skills continuum (and therefore less 'deep learning' was acquired within the group). 


\section{Quantitative assessment of knowledge gains}

The quantitative strand employed pre- and post-training questionnaires to assess how many participants had acquired new knowledge, and portfolio assessments to assess the application of this knowledge in practice.

\section{Knowledge gains assessed by questionnaires}

When considering the core group's results (Figure 2) from questionnaires across the three workshops, $61 \%$ of the participants made gains in knowledge. Closer scrutiny of the results indicates that for the first workshop $66 \%$ of the participants in both contexts showed an increase in knowledge. It should be noted that there was an absence of data for the second workshop (WS2) in the rural context because the reliability of questionnaire use in this particular context was questioned at that time. In consultation with the statistical advisor the use of questionnaires was resumed shortly thereafter. The results show that $42 \%$ of the participants in the urban context made gains in knowledge. The data for workshop 3 (WS3) show a discrepancy in knowledge gains between the semi-rural and urban context. The participants in the semi-rural area came from a much lower base than those in the urban context, and therefore made more gains. Such a discrepancy suggests that the level of prior knowledge (obtained through either formal qualifications and/or previous support provided) affected the outcomes. When considering that the participants from the two contexts were similarly qualified, it can be deducted that the participants in the semi-rural context received less prior support than those in the urban context.

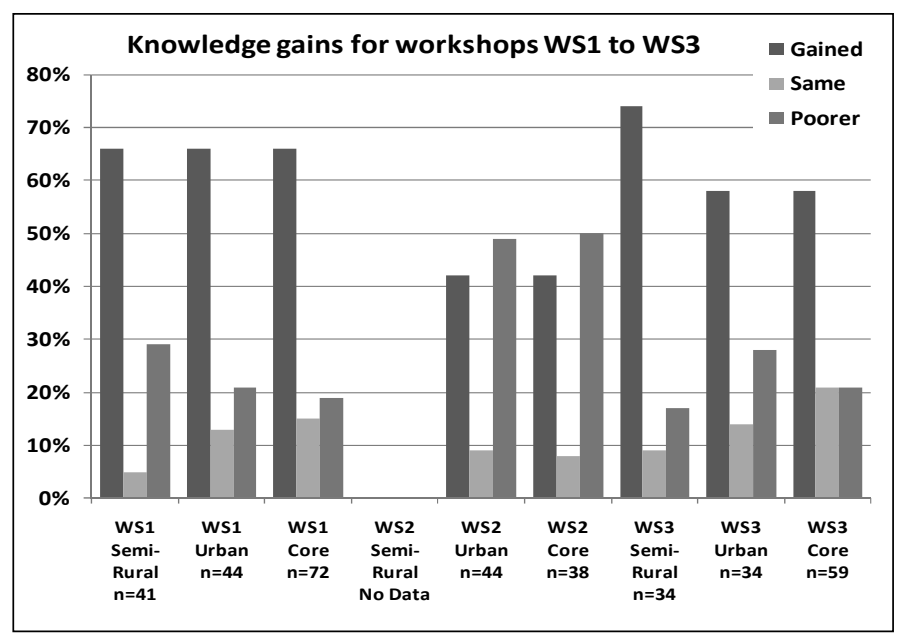

Fig. 2. Knowledge gains in workshops.

The data obtained from post-training questionnaires of how participants themselves perceived their knowledge gains differ considerably, as shown in Figure 3. These results show that in both contexts $>92 \%$ of the participants believed that they had gained in knowledge, which is much higher than what questionnaire data on actual gains had shown. This was attributed to the fact that all the participants were introduced to new ideas and observed practical demonstrations of strategies to use in class, which made them feel enthusiastic and confident. The possibility that they were trying to please the researchers should also not be excluded.

All the participants did not necessarily understand the information or know how to apply it. In addition, the use of questionnaires in these contexts was questioned. It was necessary to determine whether

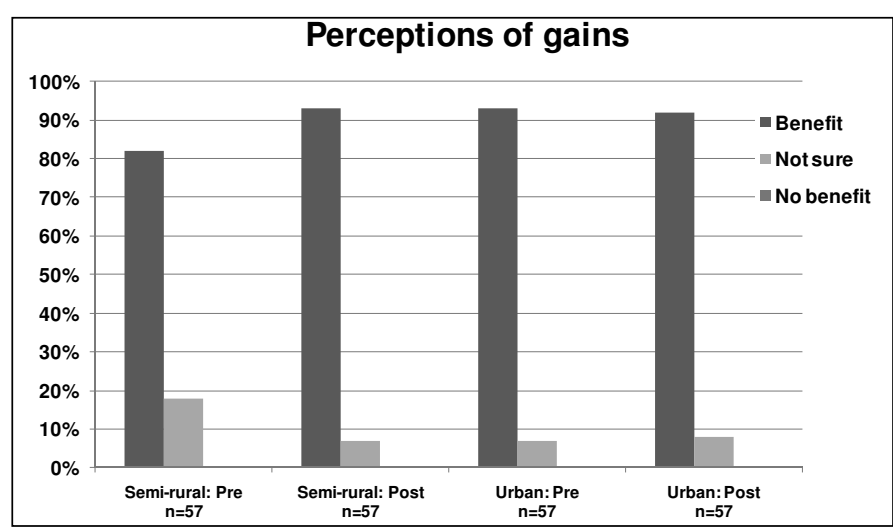

Fig. 3. Perceptions of knowledge and skill gains.

the knowledge gains measured by the questionnaires were related to knowledge applied in practice.

\section{Knowledge gains assessed by portfolio assessment}

The portfolios assessed knowledge applied in practice. An understanding of performance could be obtained by analysing the scores to show the spread of achievement. Table II depicts the ratio of participants who achieved scores above specific indicated levels.

The performance of the different categories of participants differed minimally and the general achievement was centred on $47 \%$ for both the core and 'entire' (non-core) group. Average scores higher than $60 \%$ were achieved when there were more participants in the core group ( $27 \%$ versus $19 \%$ in the 'entire' group), which indicates a better performance of participants who attended all workshops. Each workshop provided a scaffold for new knowledge to be added in the next workshop, which emphasises the importance of good attendance in support programmes. Every effort should therefore be made to limit attrition in support programmes.

When the portfolios were scrutinised for explanations for the low scores achieved by the participants, it became evident that poor achievement could be attributed to inefficiency or a slow rate of implementation. The rubric used in the assessment of the portfolios assigned scores for each week of implementation (which required a new lesson plan to be prepared within the theme of the week, accompanied with a story, song and rhyme and activities to facilitate phonological awareness skills). When the same lesson plan was used for the entire period of implementation, the portfolio was scored much lower than when a new lesson plan was developed for each of the 3 weeks. The educators in both these contexts were subjected to many challenges (e.g. language use, limited infrastructure and resources, inappropriate and/or lack of qualifications, as well as learners who were not ready for school) and therefore many of them experienced difficulty in completing the portfolio assignments according to the specifications. Such results therefore made them appear ineffective. The results shown in Table III concur that the participants have gained in knowledge and skills.

The two measuring instruments (questionnaires and portfolio assignments) assessed different aspects of knowledge, namely factual knowledge and applied knowledge (Adler et al., 2003). The results obtained with both these methods show that a relatively large number of participants performed satisfactorily and gained in knowledge and

\section{Table II. Ratio of participants with scores above the indicated average scores}

\begin{tabular}{|c|c|c|c|c|c|c|}
\hline Group & & Entire group & & & Core group & \\
\hline Indicated average score & $\overline{\text { All }}$ & Semi-rural & Urban & $\overline{\text { All }}$ & Semi-rural & Urban \\
\hline$>40 \%$ & $69 \%$ & $69 \%$ & $69 \%$ & $67 \%$ & $68 \%$ & $65 \%$ \\
\hline$>50 \%$ & $44 \%$ & $47 \%$ & $41 \%$ & $49 \%$ & $52 \%$ & $45 \%$ \\
\hline$>60 \%$ & $19 \%$ & $22 \%$ & $16 \%$ & $27 \%$ & $32 \%$ & $20 \%$ \\
\hline$>70 \%$ & $13 \%$ & $14 \%$ & $13 \%$ & $18 \%$ & $20 \%$ & $15 \%$ \\
\hline$>80 \%$ & $6 \%$ & $3 \%$ & $9 \%$ & $7 \%$ & $4 \%$ & $10 \%$ \\
\hline Average & $47.2 \%$ & $47.1 \%$ & $47.2 \%$ & $47.9 \%$ & $48.5 \%$ & $47.2 \%$ \\
\hline
\end{tabular}




\section{Table III. Corroboration of results re knowledge gains}

$\begin{array}{llll}\text { Theme } & \text { Category } & \text { Qualitative } & \text { Quantitative } \\ \text { Competency } & \text { 'Knowledge' } & 85 \% & 61 \% \\ \text { gains } & \text { 'Skills' (knowledge in practice) } & 88 \% & 47 \%\end{array}$

skills. It is, however, not possible to draw conclusions from average scores as some participants gained less than others.

\section{Attitude changes \\ Qualitative strand: confidence}

An increasing sense of professional confidence is important for learning (Graven, 2002, in Adler et al., 2003). Evidence of increased 'confidence' was noted in $88 \%$ of items coded, although the sample size was relatively small $(n=16)$. A statement such as 'I have learnt so much' from several participants in the focus groups was therefore regarded as a positive indication of increased confidence. Confidence was also inherently included in items coded in the category 'value to the educator' as items 'value of training' $(n=34)$ and 'value of training to the educator' $(n=38)$. Several participants reported in the focus groups that they had acquired more confidence by compiling the portfolio, as this required them to develop lesson plans and activities that they were unable to do before. The acquisition of self-confidence enabled some of the participants to train their colleagues. The code 'empowerment' could also be related to the development of confidence $(n=17)$. The implementation of strategies in class may have increased the participants' confidence, because they perceived themselves as being successful.

\section{Quantitative strand: confidence}

The participants rated their confidence in a self-evaluation section in the questionnaires. The results depicted in Figure 4 show that participants rated their own competence as high, but this did not correlate with their actual performance in the portfolio assessments.

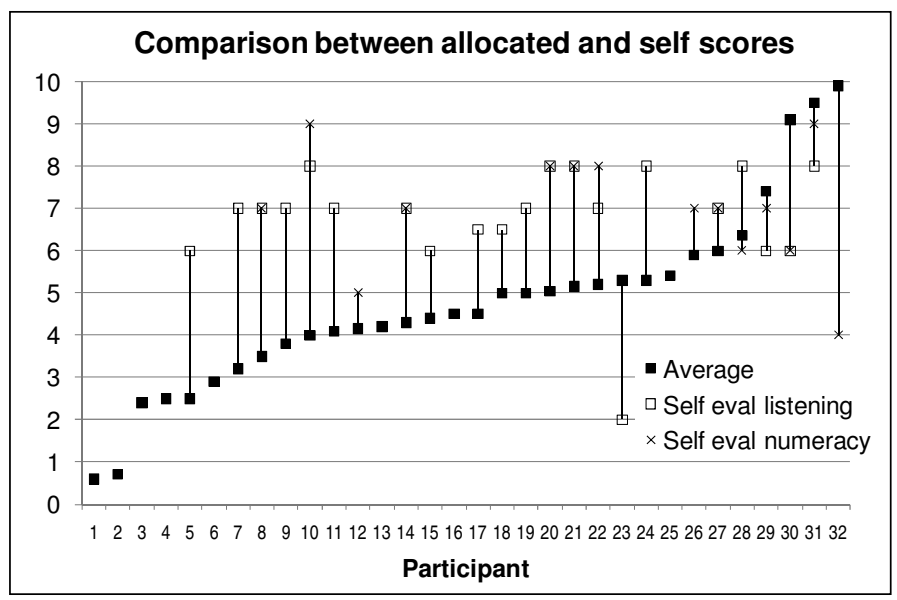

Fig. 4. Comparison of assignment scores with self-evaluation of competence.

As mentioned previously the participants who completed the selfevaluation in general judged their own competence as being high $(>70 \%)$, which indicated high levels of self-confidence in implementing the strategies learnt in the workshop. The discrepancy between confidence levels and portfolio performance may be attributed to participants' limited insight. It was taken into account that not all the participants opted to complete the self-evaluation section in the portfolio assignments, probably because they were unable to reflect on their practices or did not feel confident of their competence to implement the strategies. Reflection is an inherent part of OBE (Killen, 2007), and an inability to reflect on one's own practices could imply a need for support in this aspect.

It is possible that the portfolio scores were not a true reflection of competence in the classroom as the scores were affected by several factors (e.g. class sizes, the participants' language proficiency, prior support, factors related to timing, intrinsic motivation/attitude, school culture and school management support), which made it difficult to accurately determine the actual levels of competence.

\section{Convergence of results: confidence}

The results regarding the confidence of the participants are converged in Table IV. These results indicate high levels of confidence in both strands of the research regarding the implementation of strategies following training. The evaluation of confidence was subjective as it was based on the participants' own perceptions of their gains in confidence. In confirmation of the gains made in attitude, testimonials obtained from a group of educator support educators who unofficially attended the workshops verified the positive attitudes noted in participant feedback. Because of prolonged engagement and multiple observations across contexts (Leedy \& Ormrod, 2005), the credibility of the inferences regarding attitudinal gains was high.

\section{Table IV. Convergence of results with regard to} confidence

\begin{tabular}{lll}
\hline Aspect assessed & Qualitative & Quantitative \\
Overall confidence (total) & $88 \%(n=147)$ & $>70 \%(n=31)$ \\
Confidence & $89 \%(n=15)$ & \\
Empowerment & $100 \%(n=17)$ & \\
Implementing & $86 \%(n=102)$ & \\
Help/train colleagues & $85 \%(n=13)$ &
\end{tabular}

\section{Limitations of the research}

The following limitations were identified in the research:

- The data collection instruments were self-constructed and although all attempts were made to ensure validity, it is possible that these were subject to the trainer/researcher's subjectivity.

- All the focus groups were conducted, transcribed, coded and analysed by the trainer/researcher, and therefore the interpretations made could have been subjective.

- The high level of non-response with questionnaires and portfolio assignments was caused by several factors (language use in the CPD programme, education and literacy levels of the participants, factors related to timing and logistics).

- Attrition posed a threat to inference quality because it resulted in a reduced sample size (and therefore decreased the generalisability of the findings). An attempt was made to limit attrition by offering a certificate at completion, but this did not have the desired result.

- Neither the quantitative nor the qualitative samples in this study were randomly selected, which limited the inference quality and transferability of the findings.

\section{Conclusions}

Knowledge gains were made that could improve teaching practices. However, the participants did not make equal gains, and in several instances the gains were minimal. The participants came from diverse backgrounds and not all of them benefited from the support programme to the same extent. Although there was sufficient evidence that the participants could recall some of the terminology, there were also those who could only describe the concepts in their own words. Knowledge acquisition therefore was on the 'awareness level', which, according to Bloom's taxonomy (Anderson \& Krathwohl, 2001) of the knowledge domain, is the lowest level of acquiring new knowledge. Knowledge on the awareness level is not sufficient for participants to apply such knowledge in their classrooms (Miller \& Watts, 1990). Such low-level knowledge, together with participants' limited insight in judging their own competence, indicates a continued need for support. A stratified approach with selection criteria in terms of the educators' qualifications may result in more effective support to different groups. 
Language use in the CPD programme affected the level of understanding of concepts as English was not the L1, but an additional language for all the participants. Educators can only teach what they understand themselves. The fact that the NCS is in English may therefore present a challenge to many educators. A specific outcome of this programme was that some of the participants became inspired to improve their teaching practices, which could only benefit the learners. Evidence of increased creativity (although limited), noted when a group of educators from a specific school went to the refuse dump for polystyrene to cut out threedimensional shapes, confirmed that educators can overcome contextual challenges if they are internally motivated and have the support of their management and school-based support teams. Educator confidence is directly related to educator competence, and clear links exist between educators' confidence and their ability to facilitate learning (Killen, 2007). High levels of confidence are therefore a positive attribute of this training programme as it can be expected that learners may also benefit.

In general, the gains made in knowledge, skills and confidence with this CPD programme contributed to the professional growth of the participants. This particular three-pronged approach to educator support shows potential to yield positive results in two previously disadvantaged contexts. CPD and support of educators, however, cannot be viewed '... as a form of educator education that produces quick fixes for complex and enduring problems in schooling' (Zeichner \& Wray, 2001). Educator support should rather be seen as a continual and lifelong learning process that could motivate and empower educators to facilitate learning. Successful education reform depends on the identification and implementation of effective practices that are based on the connection between research and practice. It is therefore important that intervention programmes be evaluated for future use.

\section{Acknowledgements}

The authors wish to thank the Shuttleworth Foundation for funding the research.

\section{References}

Adler, J., Slonimsky, L., \& Reed, Y. (2003). Subject-focused INSET and teachers' conceptual knowledge-in-practice. In J. Adler \& Y. Reed (Eds.), Challenges of teacher development: An investigation of take-up in South Africa (pp.135-152). Pretoria: Van Schaik.

Anderson, L.. \& Krathwohl, D. A. (2001). A taxonomy for learning, teaching and assessing: A revision of Bloom's taxonomy of education objectives. New York, NY: Longman.

Badroodien, A., Gewer, A., Roberts, J., \& Sedibe, K. (2002). A qualitative overview of the education, training, and development practices sector: Synthesis report. Pretoria: Human Sciences Research Council and JET Education Services.

Bellis, T. (2003). Assessment and management of central auditory processing disorders in the education setting: From science to practice (2nd ed.). Clifton Park, NY: Thomson.

Botha, M., Maree, J. G., \& de Witt, M. W. (2005). Developing and piloting the planning for facilitating mathematical processes and strategies for preschool learners. Early Child Development and Care, 175(7\&8), 697-717.

Bullock, J. O. (1994). Literacy in the language of mathematics. The American Mathematical Monthly, 101(8), 735-743.

Catts, H. W., Fey, M. E., Zhang, X., \& Tomblin, J. B. (2002). A longitudinal investigation of reading outcomes in children with language impairments. Journal of Speech, Language and Hearing Research, 45, 1142-1157.

Creecy, B. (2009). Budget speech: Education vote 5. Gauteng Department of Education. Retreived from www.education.gpg.gov.za

Creswell, J. W., \& Plano Clark, V. L. (2007). Designing and conducting mixed methods research. Thousand Oaks, CA: Sage.

Davids, N. (2009). Third of SA teachers lack right qualifications. Sunday Times, 12 November (p. 6).

Department of Education Chief Directorate: Quality Assurance. (2002). National Report on Systemic Evaluation (2001) (mainstream) Gr. 3. Pretoria: Department of Education.
Department of Education Gauteng. (2007). Annual performance plan - 2007/08 to 2009/10 [Cited 2 January]. Retrieved from <http://www.education.gpg.gov.za/Publications/ Annual\%20Perfomance\%20Outcome.pdf>

Gauteng Department of Education. (1997). Curriculum 2005: Guidelines for learning programmes for the foundation phase grade one (+- first term). Johannesburg: Gauteng Department of Education.

Gawned, S. (1993). An emerging model of the language of mathematics. In J. Bickmore-Brand (Ed.), The language of mathematics (pp. 27-41). Portsmouth, NH: Heinekenn. Author: Heinemann?

Girolametto, L., Weitzman, E., Lefebvre, P., \& Greenberg, J. (2007). The effects of in-service education to promote emergent literacy in child care centres: a feasibility study. Language, Speech, and Hearing Services in Schools, 38, 72-83.

Goodman, K. (1986). What's whole in whole language? A parent/teacher guide to children's learning. Portsmouth, NH: Heinemann Educational Books.

Gouws, E., \& Dicker, A. M. (2006). Onderwysers se belewing van indiensopleiding met betrekking tot die hersiene nasionale kurrikulumverklaring: 'n gevallestudie. Tydskrif vir Geesteswetenskappe, 46(4), 416-427.

Justice, L. M., \& Ezell, H. K. (2001). Written language awareness in preschool children from low income households: a descriptive analysis. Communication Disorders Quarterly, 22, $123-134$

Justice, L. M., \& Kaderavek, J. N. (2004). Embedded-explicit emergent literacy intervention background and description of approach. Language, Speech, and Hearing Services in Schools, 35, 201-212

Justice, L. M., Skibbe, L., \& Ezell, H. (2006). Using print referencing to promote written language awareness. In T. A. Ukrainetz (Ed.), Contextualized language intervention: scaffolding pre K-12 literacy achievement (389-428). Eau Claire, WI: Thinking Publications.

Killen, R. (2007). Teaching strategies for outcomes-based education (2nd ed.). Cape Town: Juta. Leech, N. L., \& Onwuegbuzie, A. J. (2005). A typology of mixed methods research designs. Annual Meeting of the American Educational Research Association, Montreal, Canada.

Leedy, P. D., \& Ormrod, J. E. (2005). Practical research: planning and design (5th ed.). Upper Saddle River, NJ: Pearson Education.

McMillan, J. H., \& Schumacher, S. (2006). Research in education. Boston, MA: Allyn \& Bacon.

Miller, A., \& Watts, P. (1990). Planning and managing effective professional development.

Moodley, S., Chetty, S., \& Pahl, J. (2005). The school-based speech-language therapist: Choosing multicultural texts. Die Suid Afrikaanse Tydskrif vir Kommunikasieafwykings, $52,40-50$

O'Connor, J., \& Geiger, M. (2009). Challenges facing primary school educators of English second (or other) language learners in the Western Cape. South African Journal of Education, 29, 253-269.

Paradice, R., Bailey-Wood, N., \& Davies, K. 2007. Developing successful collaborative working practices for children with speech and language difficulties: A pilot study. Child Language Teaching and Therapy, 23(2), 223-236.

Pluddemann, P., Mati, X., \& Mahlalela-Thusi, B. (1998). Problems and possibilities in multilingual classrooms in the Eastern Cape. In N. Taylor \& P. Vinjevold (Eds.), Getting learning right: Report of the president's education initiative research project (p. 317-319). Johannesburg: Joint Education Trust/Department of Education.

Reed, Y., Davis, H., \& Nyabanyaba, T. (2003). Teachers' take-up of reflective practices in under-resourced multilingual contexts. In J. Adler \& Y. Reed (Eds.), Challenges of teacher development: An investigation of take-up in South Africa (p. 113). Pretoria: Van Schaik.

Richards, G. (2004). Redefining auditory processing disorder: a speech-language pathologist's perspective. ASHA Leader, 9(6), 7-21.

Roberts, J. (2002). District development: The new hope for educational reform. Johannesburg. Joint Education Trust.

Setati, M. (1999). Innovative language practices in multilingual mathematics classrooms. In N. Taylor \& P. Vinjevold (Eds.), Getting learning right: Report of the president's education initiative research project. Johannesburg: Joint Education Trust/Department of Education.

Sowden, P. (2007). Culture and the good teacher in the English language classroom. ELT Journal, 61(4), 304-310.

Steen, L. A. (2001). Mathematics and numeracy: two literacies, one language. The Mathematics Educator, 6(1), 7

The TIMMS \& PIRLS International Study Centre. (2007). PIRLS 2006 international press release. Boston, MA: Boston College in association with International Association for the Evaluation of Educational Achievement.

W. K. Kellogg Foundation. (2004). Logic model development guide. [cited 30 December 2008] Retrieved from http://www.uwex.edu/ces/pdande/evaluation/Pub3669.pdf.

Zeichner, K., \& Wray, S. (2001). The teaching portfolio in US teacher education programs: what we know and what we need to know. Teaching and Teacher Education, 17(5), 613621. 


\section{Appendix A}

Bloom's taxonomy is a classification system of learning objectives within education, which has been revised by Anderson \& Krathwohl (2001) (Figure 5). Knowledge acquisition in the cognitive domain of Bloom's taxonomy focuses mainly on knowledge, comprehension, and critical thinking of a particular topic.
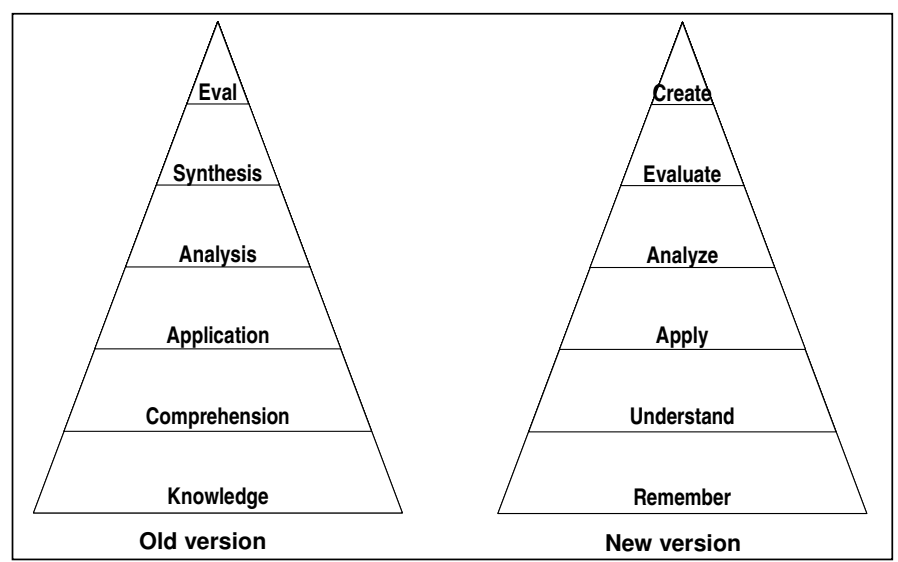

Fig. 5. Bloom's taxonomy of learning in the knowledge domain.
Knowledge is acquired sequentially in a hierarchical format, where the lower levels serve as scaffolding for the higher levels. When learning occurs on the lowest level ('knowledge'/'remember'), the learner is able to recall facts, terms, basic concepts and answers. On the second level ('comprehension') the learner is able to demonstrate understanding of the material by organising, comparing, translating, interpreting, giving descriptions, and stating main ideas. The third level in the taxonomy refers to 'application' of knowledge when the learner is able to apply his/ her knowledge by solving problems in new situations. On the 'analysis' level the learner is able to make inferences and to find evidence to support generalisations. The fifth level of the taxonomy refers to the learner's ability to synthesise the information. The learner is able to compile the information through the combination of elements in a new pattern or through proposing alternative solutions to a problem. The highest level represents the ability to evaluate the knowledge. The learner is able to defend opinions by making judgments about information. The acquisition of knowledge on this level allows the learner to validate ideas or quality of work according to specific criteria. 